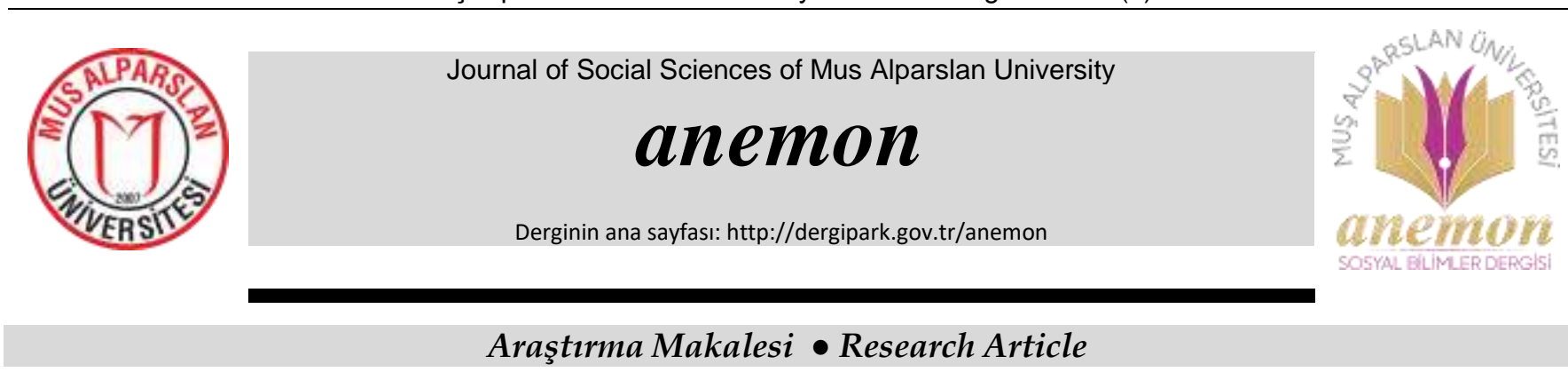

\title{
Thomas Cole ve Sanatı
}

\section{Thomas Cole and His Art}

\author{
Ufuk Çetin ${ }^{\text {a, * }}$ \\ ${ }^{a}$ Dr., Tekirdağ Namık Kemal Üniversitesi, Çorlu Mühendislik Fakültesi, Bilgisayar Mühendisliği,59860,Çorlu/Türkiye. \\ ORCID: 0000-0001-5102-8183
}

\section{MAKALE BİLGİSİ}

Makale Geçmişi:

Başvuru tarihi: 06 Kasım 2020

Düzeltme tarihi: 01 February 2021

Kabul tarihi: 08 February 2021

\author{
Anahtar Kelimeler: \\ Resim, \\ Amerikan Resim Sanat, \\ Hudson River School Ressamları, \\ 19. yüzy1l, \\ Manzara
}

\section{ARTICLE INFO}

\section{Article history:}

Received 06 November 2020

Received in revised form 01 February 2021

Accepted 08 February 2021

\section{Keywords:}

Painting,

American painting,

Hudson River School Painters,

19th century,

Landscape
ÖZ

Thomas Cole, 1801 'de İngiltere Lancashire Bolton'da doğmuş ve 1818'de ailesiyle birlikte Amerika Birleşik Devletleri'ne göç etmiş İngiliz kökenli bir manzara ressamıdır. Hudson River School olarak bilinen Amerika'nın 19. yüzyıldaki ilk manzara resim okulunun kurucusudur. Milli bir resim okulunun ortaya çıkmasını da sağlayarak insanlara çevre bilincini ve manzara resmini sanatı aracılığıyla tanıtmaya çalışmıştır. Çalışmaları 19. yüzyıl Amerikası'nda yaşanan hızlı teknolojik gelişmelere bağlı olarak insanlığın adeta eskiyi kaybederek ve kendi öz değerlerinden uzaklaştığına vurgu yapar gibidir. Ressamlığının yanı sıra yazar ve şair olarak da pek çok çalışmaya imza atmıştır. Amerikalılara bir İngiliz olarak sahip oldukları vahşi güzellikleri ve resim sanatlarını önemsemeyi hatırlatan bir yabancı ressamdır.

\section{Giriş}

Telgraf, bilimsel ve teknolojik gelişmelerin sonucu olarak, en önemli değişimi, on sekizinci ve on dokuzuncu yüzyıldaki elektrik aletleri, fiziksel olarak zihnin gizemli işleyişini ve bireyler arasındaki belirsiz, bazen şok edici bağlantıları yansitıyordu. Whitman, Melville ve Douglass gibi yazarlar, edebiyatı hem belirli ekonomik ve sosyal koşulların ürünü hem de bu koşullar tarafından belirlenen bireyi aşmanın bir yolu olarak tanımlamak için elektrik ve telgraf görüntülerinden yararlanmışlard1.

1800-1850 yılları arasındaki Amerikan resmi, bir bütün olarak, sonradan gelenlerden farklıdır. Fantastik bir meraktan farklı olarak otantik resim, küçük bir akıntı gibiydi, on dokuzuncu yüzyıl Amerikan resminin iki büyük akıntısının yanında yavaşça dolaşıyordu, biri gerçekçi, diğeri yavaş ve idealdi (Kornhauser, Ellis, Miesmer, 2003: s. 37).

\footnotetext{
* Sorumlu yazar/Corresponding author

e-posta: ucetin@nku.edu.tr
} 
İlk olarak, Hudson River School, 1825 ile tahminen 1875 arasında oluşturulan Amerikan manzara resim topluluğuna verilen bir isim olarak tanımlanmaktadır. Hudson River School gerçek bir okul değil, esas olarak New York'un Hudson Nehri vadisinde yaşayan ve resim yapan bir grup sanatçıyı belirtiyordu. Bu ressamlar sıklıkla birbirlerini tanıyan ressamlardan oluşuyordu. Birlikte eskiz gezilerine giderler, resimlerini sergi ve galerilerde yan yana sergilerlerdi. Hudson River School adı sanatçıların kendileri tarafından kullanılmadı. İsim, stillerinin popülerliğini yitirdiği bir zamanda, 1870'lerde genel olarak kullanılmaya başland.

Bu ressamların katıldıkları sergilerde Avrupa gelenekleri ile Amerika'nın çevreci ve ticari ruhunu birleştirerek kültürel değerlerin hepsini harmanladıkları izlenilmektedir. Hudson River School jeoloji biliminden yararlanılmasına ve sanayi devrimiyle yolculukların şeklinin değişmesine sebep olmuştur.Hudson River School resimleri, Amerika'nın en beğenilen ve en sevilen klasik sanat eserleri arasındadır. Thomas Cole, Frederic Church ve Albert Bierstadt gibi sanatçılar, epik eserlerinde doğaya saygı ve on dokuzuncu yüzyılın ortalarında hüküm süren "milli idealizm"i somutlaştırarak Amerikan sanatına güçlü bir miras bıraktılar.

Hudson River School ressamları görkemli, romantik, dramatik ve son derece renkli ressamlardı. Doğayı mutlu olunacak değil korkulacak ve evcilleştirilecek bir şey olarak gören bir topluluğa karşı kırsal vahşi güzellikleriyle Amerika'yı savunarak Amerika'nın tanımlanmasına da yardımcı oldular (Millhouse, 2007: s. 20).

19. yüzyılda Amerika'nın ilk sanat akımı ve ressamları hakkında çok az çocuk kitabı bulunuyordu. Yazar ve illüstratör Hudson Talbott'un "Amerika'yı Resmetmek: Thomas Cole ve Amerikan Sanatının Doğuşu" adlı kitabı bu döneme dair bilgiler sunduğu için önemli kabul ediliyordu.

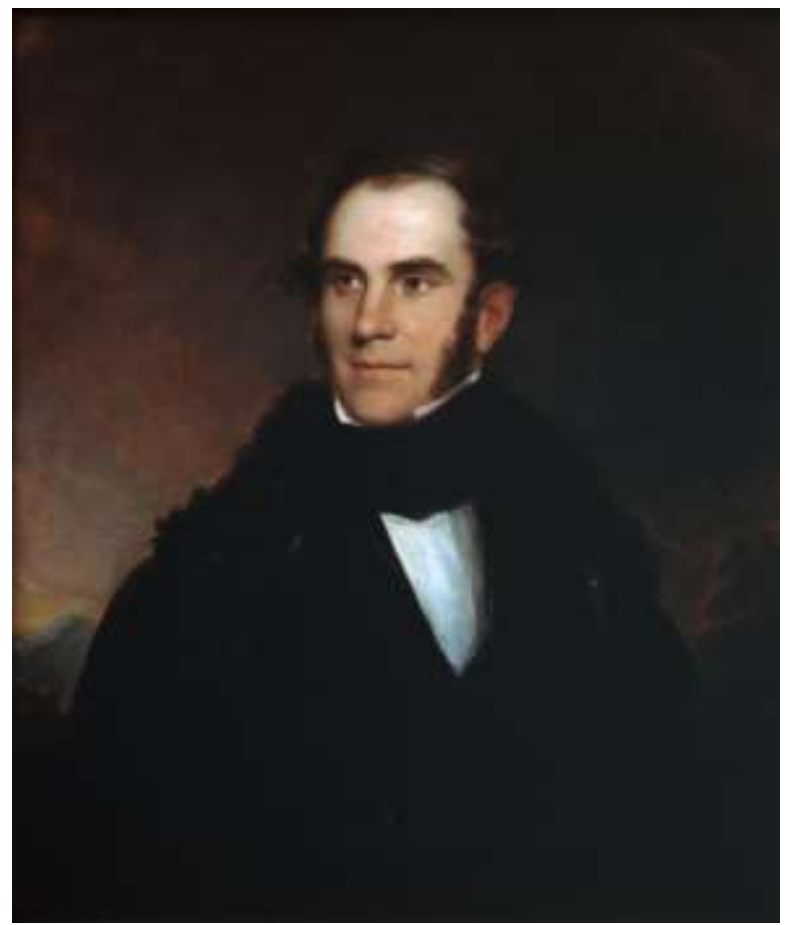

G.1.Portrait of Thomas Cole,1838, Berkshire Museum.

Aslında Hudson River School terimi ilk kez New York Sanat Eleştirmeni Clarence Cook ve manzara ressamı Homer
Dodge Martin tarafından kullanılmıştır. Bu terim başlangıçta aşağılayıcı bir şekilde kullanıldı, çünkü açık havada resim yapan ressamlardan oluşan "Barbizon Okulu" Amerikalı patronlar ve koleksiyoncular arasında revaçta olduktan sonra stil gözden düştü (Davidson, 1978: s. 43).

Hudson River School resimleri, 19. yüzyılda Amerika'nın üç temasını yansıtmaktadır; bunlar arasında icatlar, keşifler ve şehirler bulunuyordu. Ayrıca Amerikan manzarasını, insan ve doğanın uyum halinde bir arada yaşadığı pastoral bir ortam olarak da görmek mümkün olmaktadır. Hudson River School manzaraları, doğanın gerçekçi, ayrıntılı ve bazen idealize edilmiş tasviriyle karakterize edilmektedir. Genellikle bu resimlerde tarım, direnç ve kutsallık gibi özellikler Hudson Vadisi'nden hızla kaybolan vahşi doğayı yan yana getirmektedir.

Talbot "Painting America “isimli çalışmasında, Cole'un hayatının ve sanata ve doğaya olan ilgisinin izini sürmektedir.1801'de İngiltere'de doğduğu ve burada yeni doğan Sanayi Devrimi'nin İngiliz şehirlerini etkilediği durumlara tanıklık ettiği İngiltere'de başlamaktadır. Talbot ayrıca Cole'un, Amerika'da gezici bir sanatçı olarak geçimini sağlamaya çalışarak kırsalda dolaştığı ilk yıllarını da ayrıntılı olarak bu çalışmasında yazmıştır.

Hudson River School'un kurucusu Cole, 1825'te Hudson Nehri'ne ilk yolculuğuna çıktığında, önce New York'a gider ve o vapur Hudson Nehri'ne çıkar. Talbott, anlattıklarını suluboya çalışmalarıyla yansıtmıştır. Cole'un gördüğü manzarayı hayal etmiş ve ünlü bir otel olan Catskill Dağ Evi'nin de dâhil olduğu bir düzineden fazla Cole'un eserinin reprodüksiyonlarını da Painting Americ simli çalışmasına eklemiştir. Sanatçılar arasında popüler olan Kaaterskill Clove; ve iki alegorik serisi, "The Course of Empire" ve "The Voyage of Life"dan da bahsetmiştir.

Thomas Cole, Hudson Nehri Okulu olarak bilinen Amerikan manzara ressamlarına ilham vermiştir. 1801 yılında Birleşik Krallık İngiltere'nin Lancashire şehrinde Bolton-leMoors'ta doğmuştur. On yedi yaşındayken ailesiyle birlikte Amerika Birleşik Devletleri'ne göç etmiştir. İlk olarak Philadelphia'da Steubenville'de, Ohio'ya gitmeden önce, ahşap oymacı olarak çalışmıştır.

Önceleri duvar kâğıdı imalat işiyle ilgilenmiş ancak bundan memnun olmayan Cole, bir sanatçıdan siparişler alarak, portreler, ölü doğa resimleri ve birkaç manzara resmi yapmaya başlamıştır. Geçimini sağlamak için Ohio’ya gitmiştir.1823 yılına geldiğinde, ailesinin sonradan yerini değiştirdiği Pittsburgh'da babasıyla tekrar çalışmaya başlamıştır (Baigel, 2000: s. 45).

Daha sonra Güzel Sanatlar Akademisi'nde gördüğü resimlerden esinlenerek sanatını sürdürmek için Philadelphia'ya taşınmıştır. 1825 yılının baharında New York'a taşınan Cole, yakın zamanda açılan Catskill Mountain House otelinin yakınındaki Hudson Nehri'nde doğu Catskill Dağları'na bir gezi yaptı. Oradaki ve nehir üzerindeki eskizlerine dayanarak, bir kitapçının vitrininde sergilemeyi kabul ettiği üç manzara resmi daha yaptı (Legrand, 1997: s. 17).

Zaten Amerikan Devrimi'nin ressamı olarak bilinen Albay John Trumbull, Cole'un resimlerini görmüş ve görür görmez hemen bir tane resim satın alarak diğer ikisini de meslektaşları William Dunlap ve Asher B. Durand'a tavsiye 
etmişti. Trumbull'un genç ressamın çalışmasında farkettiği şey, manzara sanatçılarının daha önce görmemezlikten geldiği Amerikan manzarasının doğasında var olan vahşilik algisıyd1.

Trumbull gibi, Cole'un çalışmalarını hevesle satın almaya başlayan çeşitli müşterilerin de dikkatini de çekmişti. Dunlap, yeni yeteneklerin keşfini duyurdu ve Cole, şair ve editör William Cullen Bryant ve yazar James Fenimore Cooper'ın da aralarında bulunduğu New York'un sanat ve kültürel çalışmalar topluluğu tarafından hayranlıkla karşılandı. Cole, 1825'te Milli Tasarım Akademisi'nin kurucu üyelerinden biri oldu (Parry, 1986: s. 39).

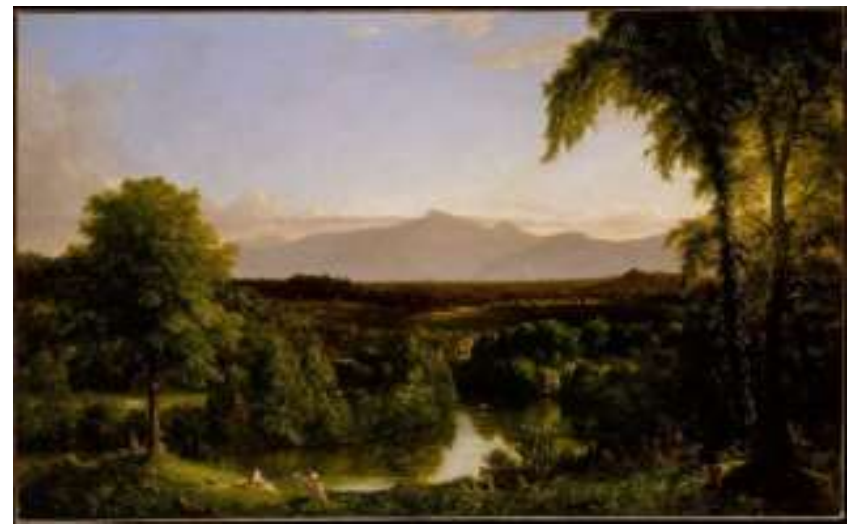

G.2.Thomas Cole, View on the Catskill-Early Autumn, 1836. The Metropolitan Museum of Art.

Cole, New York'taki Hudson Nehri'ni çevreleyen dağları ve yemyeşil vadileri resimleyerek, zamanının çoğunu Catskill Creek kıyısındaki Catskill kasabası yakınlarındaki evinde geçirdi. Bununla birlikte, 1837 'de, manzara artık bu tuvaldekine benzemiyordu. Canajoharie ve Catskill Demiryolu vadinin tam ortasında yapılarak yüzlerce ağaç kesildi. Aynı zamanda bir şair ve deneme yazarı olan Cole, umutsuzluk içinde yazmaya devam etti.

Ressam Thomas Cole'un evi olan Cedar Grove, Catskill, New York'ta bulunan stüdyosu çeşitli hikâyelerle doludur. Fırçaları, paletleri ve stüdyosu ile Amerika'nın ilk manzara ressamının etkileyici tablolarını nasıl yaptığına dair ipuçları vermektedir. Cole hem vahşi hayatı hem de pastoral manzaray1, özellikle Hudson Nehri Vadisi ve Catskill Dağları'nı çalışmalarında kullanmıştır. Ayrıca çocukluk, gençlik, olgunluk ve yaşlılığı temsil eden figürlerin kendi tabiriyle hayat nehri üzerinde yolculuk yaparken resimlerini tasvir ettiği dört farklı resmin bir araya getirilmesi ile oluşmuş "The Voyage of Life" gibi alegorik resimler de yapmiştır.

Cole, Amerika'nın ilk yerli sanat hareketi olan Hudson River School olarak kabul edilen bir grup yetenekli sanatçıya ilham vermişti. 1818'de İngiltere'den göç etmeden ve Amerikan vahşi doğasını keşfetmeden önce hiç resim yapmamış, kendi kendini yetiştirmiş ve kendi kendini yetiştirmiş bir sanatçı olarak ünlenmiştir. Kalıcı bir gizem, sanatını çevrelenmiş durumdadır. Sıradışı manzaraları 1825'te New York sanat sahnesinde dikkat çekmeden önce kendisini yalnızca birkaç y1l resme adamıştı. Görünüşe göre eğitimsiz bir sanatçının bu kadar hızlı bir şekilde bu kadar güçlü bir iş yaratmaya başlaması oldukça şaşırtıcıydı.
Günümüzde, Cole'un resimleri milyonlarca dolar değerinde kabul edilmektedir."The Voyage of Life özellikle oldukça popüler bir çalışmasıdır.

\section{Sanatı}

Thomas Cole (1801-1848), popüler Hudson River Resim Okulu'nun kurucusu olarak kabul edilir. 1819'da İngiltere'den Amerika Birleşik Devletleri'ne göç eden Cole, 19. yüzyıl boyunca Amerikan resmini karakterize edecek ve resimleri Amerikalıların ve dünyanın genç ülkeye bakışını değiştirecek bir manzara tutkusu uyandırdı (Noble, 1856/2009: 26).

Cole, Sanayi Devrimi'nin neden olduğu zararın İngiltere'de net olduğu ve Amerika'nın Yeni Dünyasında henüz hissedilmeye başlandığı bir zamanda Atlantik'i geçip kişisel yolculuğunu çalışmalarında yansıtan bir ressamdı. İnsan ve doğa ilişkisindeki bu dramatik değişimin ekolojik ve sosyal bedellerine dair uyarılarını resimlerinde ve yazılarında yayınladı. Cole'un Amerika'nın vahşi doğasına olan sonsuz tutkusu, bu resimlerde, arazinin kontrolsüz gelişiminin ağır ekolojik maliyeti konusunda Amerikan vatandaşlarına ateşli görsel uyarılarda bulunuyordu. Bir millet olarak, diğer ressam ve yazarlar üzerindeki etkisiyle Amerikan kültürüne yayılmasına rağmen, uyarısına pek aldırış edilmemişti. Görüşleri ve çevresel uyarıları bugün hala son derece geçerli durumdadir.

Thomas Cole her zaman çizecek yeni bir şeyler arıyordu. Sanayi Devrimi sırasında İngiltere'de doğmuş, Amerika kırsalındaki hikâyelerden büyülenmişti ayrıca 1818'de Amerika kıtasına taşınmaktan çok mutluydu. Bir sanatçı olarak hayatı ilk başta zordu, ancak Thomas sürekli çizim yaparak ve başkalarını arayarak hayalini canlı tuttu. Ancak, Catskill Dağları'nın vahşi doğasını görmek için Hudson Nehri'nde bir tekne turu için bilet verildiğinde onun için her şey değişti. Manzaranın unutulmaz güzelliği onun hayal gücünü ateşledi ve hayatının geri kalanı için ona ilham verdi. Ardından gelen görkemli tablolar, Amerika'da doğan ilk sanat akımında, halkın akınına uğradı ve diğer sanatçıları da onun izinden sürükledi. Manzara resimleri, ülkenin vahşi güzelliğinin nasıl korunacağına dair bir tartışma başlattı.

The Course of Empire, 1833-1836 yıllarında Thomas Cole tarafından yaratılan beş tablodan oluşan bir seridir. Kısmen, birçoğunun pastoralizmi insan uygarlığının ideal aşaması olarak gördüğü, imparatorluğun açğözlülüğe ve kaçınılmaz çürümeye yol açacağından korktuğu zamanların yansıması olarak popüler Amerikan duygularını yansıtması dikkate değerdir (Wilton, 2002: s. 42).

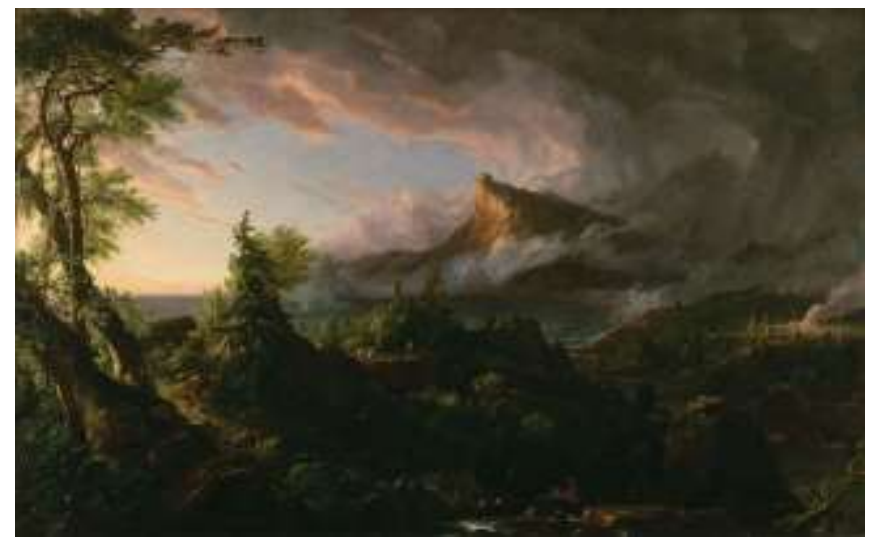


G.3.The Savage State from The Course of Empire,1834, The Metropolitan Museum of Art.

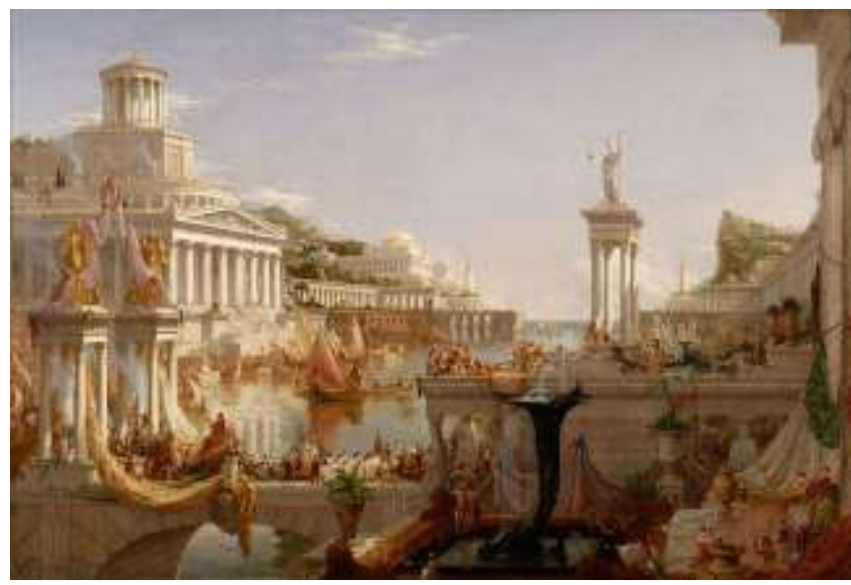

G.4.The Consummation of Empire from The Course of the Empire, 1836, New-York Historical Society.

Cole çalışmalarında Amerika Birleşik Devletleri'nin milli manzara resmi olarak benimsenen şeyin kökenlerinin doğal güzellikte değil, incinmiş onurunda yatmakta olduğunu belirtiyordu. 1829 'da, bir İngiliz gezgin ve Napolyon Savaşları'nın emektar Kaptanı Basil Hall, 1827 ve 1828 Yıllarında Kuzey Amerika'da Seyahatler isimli çalışmasını yayınladı. Hall'un genç Amerikan ulusu hakkındaki yorumları, Amerikalıların maddiyata takıntılı olduğu ve sadece sınırlarda sert olmakla kalmayıp aynı zamanda siyasi ve kültürel kurumlarının da Avrupa'dakilerden daha kötü durumda olduğu gibi fikirlerini içeriyordu (Noble, 1856/2009: s. 34).

The Voyage of Life, 1842'de Thomas Cole tarafindan oluşturulan ve insan yaşamının aşamalarının bir alegorisini temsil eden dört resimden oluşan önemli ve ilgi çekici bir seridir. Resimler, Çocukluk, Gençlik, Olgunluk ve Yaşlılık bölümlerinden oluşuyordu.Bu resimler de 19. yüzyılın ortalarında Amerikan vahşi doğasında bir nehirde bir teknede seyahat eden bir gezgini tasvir ediyor. Her resimde yolcu, bir koruyucu melek eşliğinde Yaşam Nehri üzerindeki tekneye biniyor. Her biri yılın dört mevsiminden birini yansıtan manzara, hikâyenin aktarılmasında büyük rol oynar. Her bölümde, teknenin gidiş yönü önceki resmin tersine çevrilir. Çocuklukta bebek karanlık bir mağaradan zengin, yeşil bir manzaraya kayar. Çocuk, gençken teknenin kontrolünü ele alır ve gökyüzünde parlayan bir kaleyi hedefler. Olgunluk döneminde yetişkin, dalgalı sularda ve tehdit edici bir manzarada onu ayakta tutmak için dua ve dini inanca güvenir. Sonunda adam yaşlanır ve melek onu sonsuzluğun sularında cennete götürür.

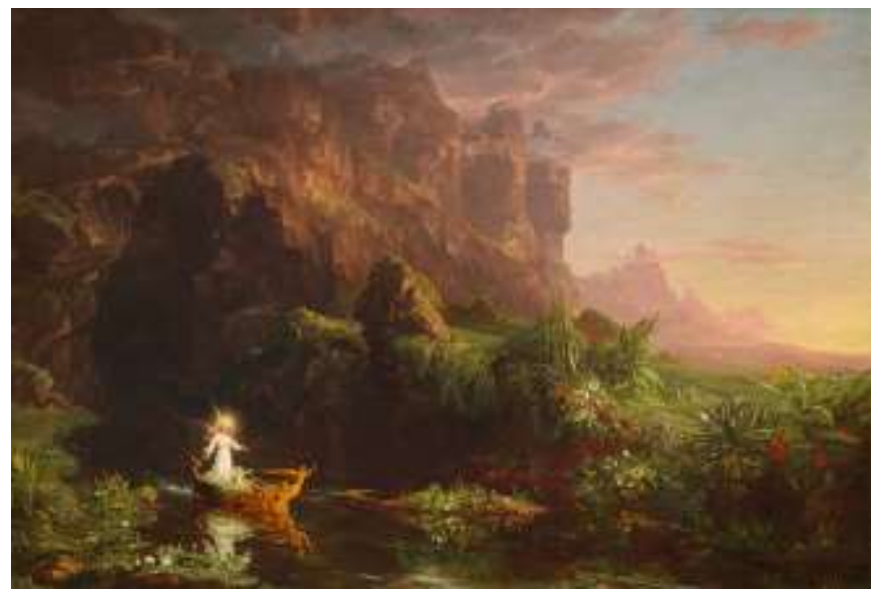

G.5.The Voyage of Life: Childhood,1840,National Gallery of Art.

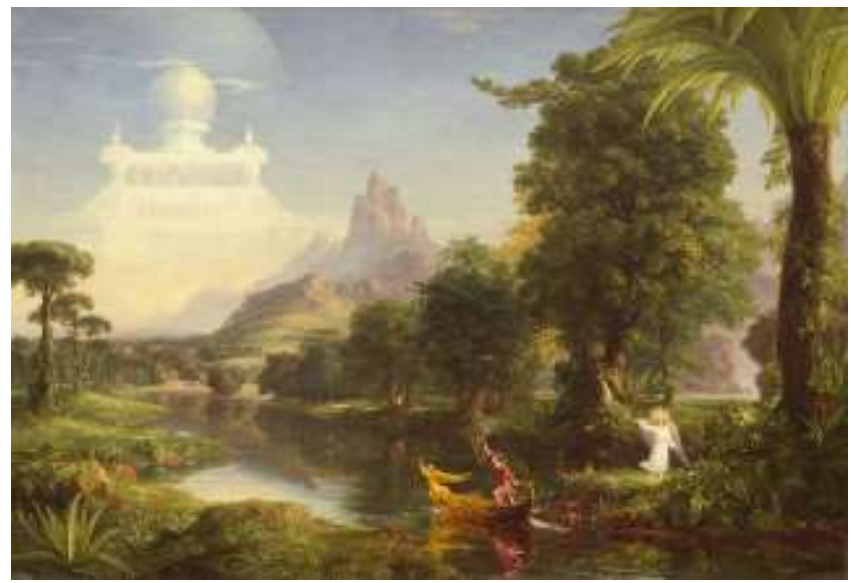

G.6.The Voyage of Life: Youth, 1842, National Gallery of Art.

Cole seyahatlerini ve konularını New Hampshire'ın White Mountains'ındaki sahneleri içerecek şekilde genişletse bile, İncil ve edebi konular da dâhil olmak üzere anlatımı içeren daha üst düzey olarak kabul edilen manzara tarzındaki resimlerle yapmıştı.1829'a kadar başarısı devam ederek, Avrupa'da, özellikle 1831-32 yıllarında kaldığı İtalya, Floransa, Roma ve Napoli'yi ziyaret ettiği Büyük Tur'a katılmasını sağlamıştı. Daha sonra birçok İtalyan temaları ile ilgili resimler yaptı. Metropolitan Müzesinde bulunan 1832 tarihli "Tivoli'de Sabah" adlı çalışması buna bir örnektir. Roma çevresindeki bölge, klasik efsanesi ile birlikte müzenin hayali Titan's Goblet'e (1833) ilham vermiştir (Parry, 1989: s. 52).

Cole'un seyahatleri ve New Yorklu tüccar Luman Reed'in cesareti ve desteği, en iddialı tarihi manzara serisi olan The Course of Empire (1833-36; New-York Tarih Derneği), eski bir klasiğin yükselişini ve düşüşünü dramatize eden beş resim ile doludur.

Cole ayrıca, sürekli geliştirdiği tekniğiyle, bir firtınadan sonra Northampton, Massachusetts'ten Gösterişli Amerikan sahneleri gibi etkileyici Amerikan sahneleri yapmaya devam etmişti. Maria Bartow manzarayı resmettiği bir portre de dâhil olmak üzere Oxbow, Catskill Overview - Early Fall (1836-37) ve "View of the Catskill Mountains" bir yil önce taşındığı ve karısıyla tanıştığı yer olan Catskill köyünü pastoral olarak yorumlamış̧ı (Powell, 2000: s. 22).

Cole, 1826'da Hudson Nehri'nin batı kıyısındaki New York'un Catskill köyünde evini yapmıştı. Oradan sık sık kuzeydoğuya, özellikle yürüyerek, karakalem manzara resimleri yaptı. Bu eskizleri kışın stüdyosunda resim yapmak 
için kulland1. Cole'un en etkili manzara resimlerinden biri olan Ox-Bow (1846), Massachusetts'te yaptığ 1 karakalem çalışmalarının sonuncusuydu (Truettner, 1994: s. 64).

Cole'un, büyük bir saygıyla tarihe geçen Hudson Nehri vadisinin sahneleri, Kuzey Amerika ormanlarının yalnızlığını ve gizemini yansıtmaktadır. Cole, ayrıntılı ve doğrudan aktarılmış manzaraları küçük ayrıntılarla oluşturarak aynı zamanda 1şığın ve chiaroscuro'nun cesur etkilerini kullanmasıyla görkemli ve dramatik hayali manzaralar üretmiştir. Çalışmalarında teknik olarak daha çok Chiaroscuro tekniğini kullanmıştır. Chiaroscuro kelimesi İtalyanca "açık-karanlık" anlamına gelir. Chiaroscuro, sanatçının derinlik ve hacim duygusu yaratmak için ışığı ve karanlığı karşılaştırdığı bir boyama tekniğidir. Bu yoğun gölgeleme kullanımı, Cole'un "The Course of Empire: Destruction" (1836) resminde olduğu gibi, bir resmi daha dramatik ve adeta net olmayan hale getirmektedir.

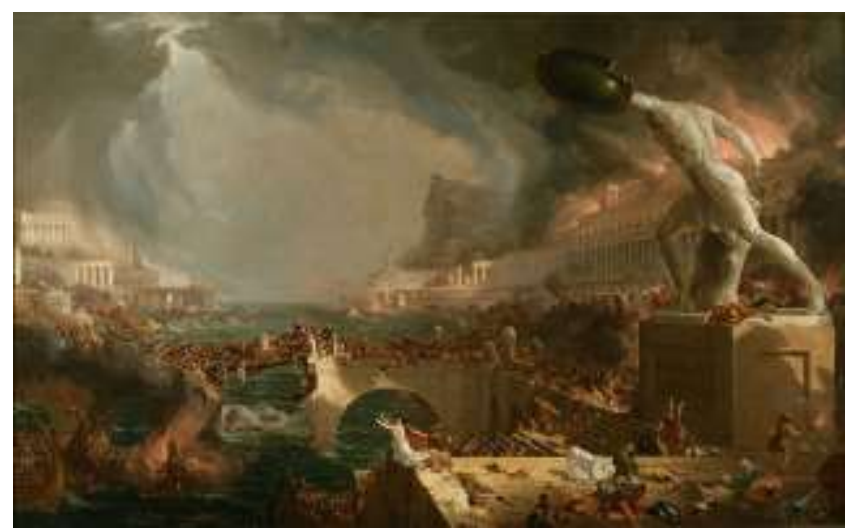

G.7.The Course of Empire: Destruction.1836, The New-York Historical Society.

Cole görünüşe göre iddialı alegorik çalışmalarını tercih ediyordu, ancak çoğunlukla Amerikan macera ve keşif ruhunu çağıran vahşi ve ülkenin geniş manzaralarıyla dramatik manzaraları ile beğenilmiştir.

Cole 1836 tarihli bir denemesinde "Amerikan manzarasının en ayırt edici ve belki de en etkileyici özelliği vahşiliğidir" diye yazmıştır. Kendisine göre bu durum en belirgin olanıydı çünkü uygar Avrupa'da manzaranın basit özellikleri çoktan yok edilmiş veya değiştirilmişti." Toprağın kendisinin ilkel doğasına ilişkin güçlü anlayışıyla Cole, haklı olarak Amerikan manzara resminin kurucu babası olarak adlandırılabilir. Çalışmaları, Yeni Dünya'nın vahşi doğasının ihtişamını, onu Avrupa resminden ayıran bir doğrudanlık ve canlılıkla aktaran bir sanatçıydı. Yine de hırsı arttıkça, Cole'un çalışmaları, ticareti artan, genişleyen sanayileşmeyi ve kazanç arayışla doğal ortamların yok edilmesini benimsenmesi ile yeni Amerikan değerlerinin şiddetli eleştirisini oluşturdu.

Cole'a göre insan figürü eserlerinin görünümü, her zaman çevredeki manzaranın görkemine bağlıdır.

Sanatçının evliliği, dört bölümlük "The Voyage of Life çalışması" (1840; Munson-Williams-Proctor Enstitüsü, Sanat Müzesi, Utica, N.Y.) dini özellikleri de beraberinde getirmişti. İçinde bir nehir yolculuğu, insanın yaşam boyunca sonsuz ödüle geçişini temsil eder. Cole, 1841-42'de güneye Sicilya'ya seyahat ettiği Roma'daki serinin bir kopyasını yapıp sergilemiştir. Döndükten sonra, başta Durand aracılığıyla New York'ta sanat etkinliğine ayak uydurarak öncelikle Catskill'de yaşamış ve çalışmıştır. "Ford Mountain" de (1846) dâhil olmak üzere, farklı güzellikteki Amerikan ve yabancı manzara resimleri yapmaya devam etmiştir.

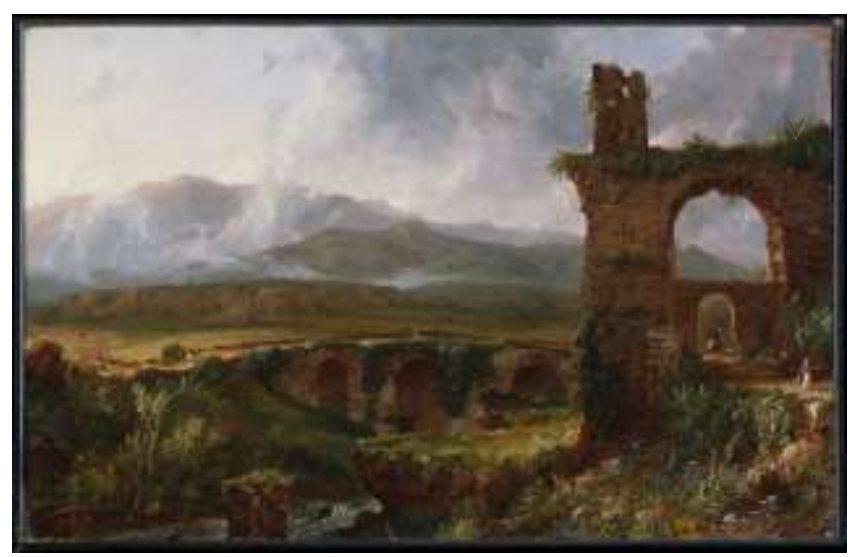

G.8.Thomas Cole, A View near Tivoli (Morning),1832, The Metropolitan Museum of Art.

Cole, İngiltere'de doğmuş ardından Avrupa'ya iki ziyaret yapmış ve burada da Amerikan manzaralarıyla birlikte çeşitli manzara resimleri yapmıştır. İtalya'nın manzaraları özellikle ilgisini çekmiş ve bu yüzden Claude Lorrain gibi Avrupalı ustaların sanatsal bazı resimlerini de yapmıştır. 1832 yılının baharında Roma Campagna'da eskizler hazırlamış, ancak Haziran ayında Floransa'ya dönene kadar bu resimleri tamamlamamıştır. Daha sonra 1834'te eseri bir mektupta şöyle anlatmıştır. Tivoli yakınlarında bir köprüyü temsil eden bir görünüm ve "Il Arco di Nerone" adlı eski bir su kemerinin bir parçası olan bu kemerin altından bir yol geçer; sisler ise dağlardan yükselen bir sabah sahnesidir diye bahsetmektedir.

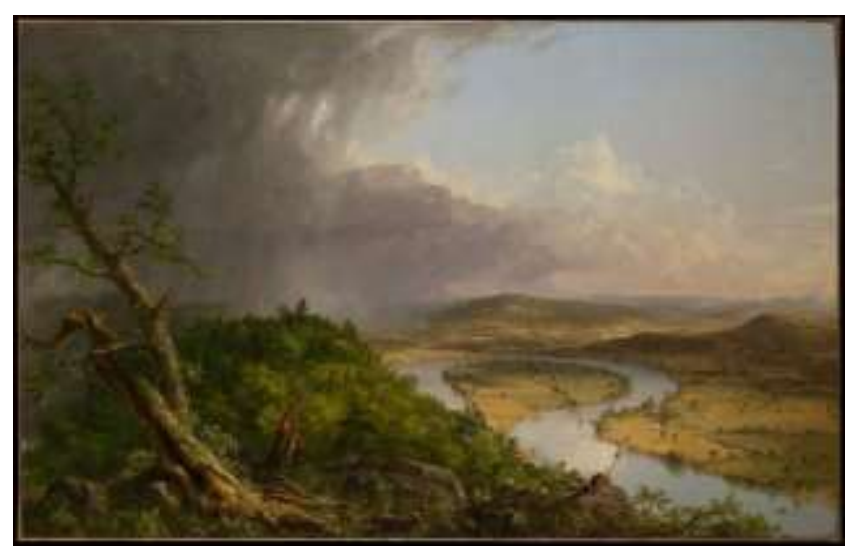

G.9.Thomas Cole, View from Mount Holyoke, Northampton, Massachusetts, after a Thunderstorm-The Oxbow,1836, The Metropolitan Museum of Art.

Uzun zamandır The Oxbow olarak bilinen bu çalışma, yorumlarla dolu Amerikan manzara resminin bir şaheseri olarak kabul edilmektedir. The Course of the Empire (New York Tarih Derneği) resminin ortasında Cole, 2 Mart 1836 tarihli bir mektupta patronu Luman Reed'e bu konunun büyük bir versiyonunu açıkça sergi ve satış için yaptığını belirtmiştir. Resim 1836'da Milli Tasarım Akademisi'nde Firtınadan sonra Northampton, Massachusetts, View from Holyoke Mountain olarak gösterilmiştir. Cole'un konuya ilgisi muhtemelen 1829-32 Avrupa gezisinden 
kaynaklanmıştı. Bu sırada Basil Hall'un Kuzey Amerika'da 1827 ve 1828 'de Kamera Lucida ile Yapılan Kırk Dağlar'da yayınlanan görüşlerinin izini sürmüştür. Hall, Amerikalıların manzaralarına karşı olan ilgisizliğini eleştirmişti. Oysa Cole, manzara resimlerine, kutsal ve gösterişli bir anlam yükleyerek Amerika'nın benzersizliğine övgü dolu bir manzara ile karşılık vermişti. Arazinin önemsenmemesi konusu genellikle belirsiz olmasına rağmen, burada sanatçı, Amerikan halkının gelecekteki beklentisine işaret ederek milli manzara görünümlerini vurgulamak için evcilleştirilmemiş vahşi ve pastoral yerleşimi yan yana kullanmayı tercih etmişti. Cole'un ahlaki öneme sahip, tartışmasız sahnesi ve kompozisyonu, orta mesafedeki kendini tasvir ederek, Oxbow'u süsleyen bir burun üzerine oturtulmuş durumdadır. Amerikan manzarasıyla birlikte Amerikada üretilen bir Amerikan sanatı olarak görülmeye başlanmıştır.

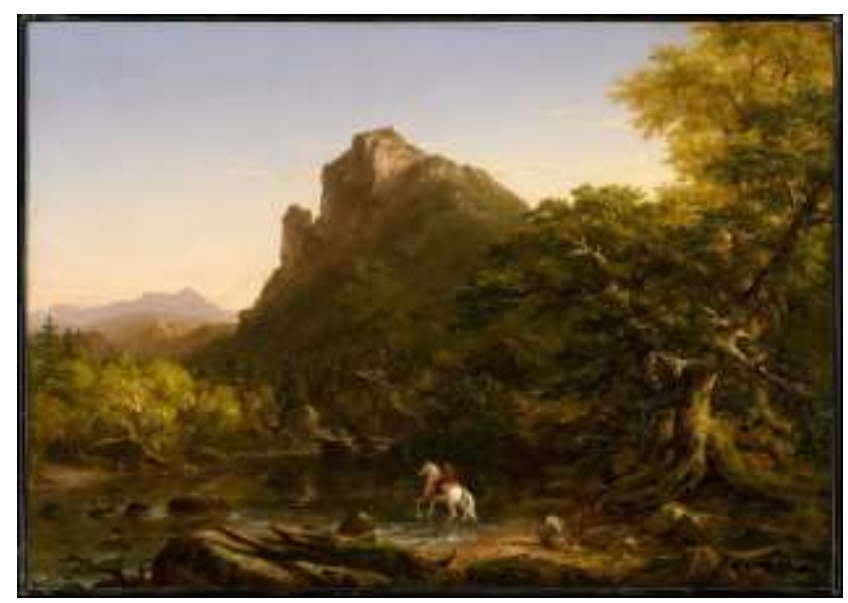

G.10.Thomas Cole, The Mountain Ford,1846, The Metropolitan Museum of Art.

Cole'un ölümünden iki yıl önce yapılmış olan bu resim, ima edilen sembolik bir anlamla tamamen hayal edilmiş bir görüntünün kaydı gibi görünmektedir. Zirvesinde 1 şı ve üstündeki gölgeyle merkezdeki dağ, etrafındaki ormanı güçlü göstermektedir. Uygarlık saf doğa üzerinde hiçbir iz bırakmamış durumdadır. Bununla birlikte,resimde karanlık bir su kütlesinin kenarında, kararsız birşekilde beyaz bir dağda yamacında bir süvari belirir, karanlık ve korkutucu derinlikleri kırmak için içeri girmeden önce geçici olarak duraklar durumdadır. İnsanın ve vahşi doğanın bu yüzleşmesi, yalnız binicinin harika bir dünyaya yolculuk etmesinin uzun alegorik bir geleneğine dayanmaktadır.

\section{Sonuç}

Thomas Cole 1801-1848 yıllarında yaşamış Amerikalı bir ressamdır. 19. yüzyılın ortalarında manzara çizen bir grup Amerikalı sanatçıdan oluşan Hudson River School'un sanat eleştirmeni ve kurucusu olarak seçilmiştir. Bu sanatsal hareketin ressamları, resimlerinde hem doğal, hem de idealize edilmiş Amerikan doğasına ait gerçekçi, ama anıtsal ve romantik çalışmalarıyla ünlü olmuştur.Çalışmada kullanılan fotoğraflar alıntıdır.

Thomas Cole'un, en önemli özelliği bir manzara sanatçısı olarak resimlerinin çoğunda karakteristik alegorik bir hayal gücü bulunmasından kaynaklanmaktadır. Sanatçı, en çok "The Course of the Empire" isimli beş bölümlük dizisiyle tanınıyordu. Dört resimden oluşan bir başka popüler dizi, bugün iki tanesi günümüze ulaşmış "The Voyage of Life" olarak tanınmaktadır. $\mathrm{Bu}$ çalışmalar kendisini ünlü ve popüler hale getirmiştir.

1846'ya gelindiğinde Cole, en büyük ve en iddialı dizisi "The Cross and the World" üzerinde çalışıyordu, ancak Şubat 1848 'de akciğer zarı iltihaplanmasından hayatını kaybettiğinden çalışmasını tamamlayamamıştır. New York'taki bir anıtta, "Böyle bir adam öldüğünde doğa cazibesinden çok fazla şey alındığı için yas tutmaya başlamıştır." diye yazmaktadır. Ancak Cole'un gelecek yıllarda sanatta büyük bir usta olarak saygı gösterileceği düşüncesiyle çevresindekiler teselli edilmiştir. Cole'un ölümünden önce bile, 1830'ların sonlarında Cole ile seyahat eden ve çizim yapan ve kendi de bir manzara ressamı olan eski muhtar Durand, Milli Tasarım Akademisi başkanı olmuştu. Durand, Cole'un İç Savaş dönemi boyunca Amerikan sanatındaki önceliğe örnek teşkil eden genç nesil manzara ressamlarının enbaşında geldiğinden bahsetmiştir. Araştırmamızda kullandığımız resimler değerlendirildiğinde sanatı ile ilgili olarak oldukça gerçekçi çalışmalar ortaya koyduğu ve çoğunlukla doğrudan açık alanda gözlem yaparak resimlerini yaptığ 1 görülmektedir. Ancak sembolik ve daha çok hayal gücünün de kattığı anlamlarla oluşturduğu resimlerinden de örnekler verilmiştir. Resimler incelediğinde anlık görüntülerin bir kamera yardımıyla ölümsüzleştirilmiş gibi son derece gerçekçi oldukları görülür. Resimlerinde gerçeklik olgusunu yansıtmada ve renk seçimi konularında başarılı olduğu görülmektedir. Teknik olarak chiaruscuro tekniğini kullanmıştır. "The Voyage of Life" ve "The Course of Empire" isimli çalışmaları oldukça popülerdir. Yapılan bu çalışmayla kendisi ve sanatı ile ilgili alan yazınına güncel bir Türkçe kaynak sunulmuş olup; konuya ilgi duyan yeni araştırmacılara yardımcı olacağı umulmaktadır. Amerikan manzara resim sanatında ilk çevreci ressam olarak yapmış olduğu bu resimleri yalnızca Amerika kıtasında değil, Avrupa ve diğer kıtalarda da karşılık bularak yeni çevreci ressamların ortaya çıkmasını sağlamıştır. Renkleri oldukça doğal bir şekilde doğada, açık alanda doğrudan gözlemlediği gibi yansıttığından, çalışmaları son derece doğal olarak görülmektedir. Cole bir ressam olarak resimleriyle insanoğluna yaşanılan hızlı ve teknolojik gelişmelere bağlı olarak bu doğal güzelliklerin yok olmasını hatırlatmaktadır. Cole ayrıca yalnızca insanlara değil, pek çok canlı türüne ev sahipliği yapan doğal güzelliklerin yok olmasına engel olmaları için bireyleri bilinçlendirme konusunda sanatı ve bilimi bir arada kullanarak öncü bir rol üstlenmiştir.İlk manzara resmini Amerika'dan dünyaya çevre bilinciyle birleştirerek sanatını bu amaçla kullanmayı tercih etmiş sıradışı bir ressamdır.Bu görüşlerini yalnızca yapmış olduğu resimleriyle değil yazmış olduğu yazı,şiir ve derlemeleriyle de desteklemiştir.

\section{Kaynakça}

Baigell, M. (2000). Thomas Cole (Famous Artists). WatsonGuptill.

Davidson, A. A. (1978). The Eccentrics and Other American Visionary Painters. New York: E.P. Dutton. 
Kornhauser, E. E., Ellis, A., Miesmer, M. (2003). Hudson River School: Masterworks from the Wadsworth Atheneum Museum of Art. Yale University Press.

Noble, L. L. (1856/2009). The Life And Works Of Thomas Cole. Kessinger Publishing.

Nygren, E. J.(1986) Views and Visions: American Landscape before 1830. Exhibition catalogue. Washington, D.C.: Corcoran Gallery of Art.

Parry, E. C. III. (1986). Thomas Cole's Early Career: 18181829.

Parry, E. C. III. (1989). Thomas Cole: Ambition and Imagination. Newark: University of Delaware Press.
Legrand, N. L. (1997). The Life and Works of Thomas Cole. 1853. Hensonville, New York: Black Dome Press.

Millhouse, B. B. (2007). American Wilderness: The Story of the Hudson River School of Painting. Black Dome Press.

Powell, E. A. (2000). Thomas Cole. Harry N. Abrams.

Truettner, W. H. and Alan W. (1994). Thomas Cole: Landscape into History. Exhibition Catalogue. New Haven: Yale University Press.

Wilton, A. ve Barringer, T. (1820-1880/2002). American Sublime: Landscape Painting in the United States. Princeton University Press. 


\section{Extended Abstract}

Thomas Cole is a British landscape painter who was born in 1801 in Lancashire Bolton in Northwest England and immigrated to the United States with his family in 1818 . He was the founder of the first landscape painting school in America known as the Hudson River School in the 19th century.Besides, the first native American landscape painting started with the Hudson River school that he founded. He also tried to introduce environmental awareness and landscape painting through his art by establishing a national painting school. His works seem to emphasize that due to the rapid technological developments in 19th century America, humanity has almost lost the old and moved away from its own values. In addition to his painting, he has also made many works as a writer and poet. Although primarily selftaught, Cole has also worked with members of the Philadelphia Academy and his work has been included in the Academy's exhibitions. In 1825, Cole discovered the stunning beauty of the wild nature of the Catskill region of the Americas, a foreign painter who reminded Americans to care about the wild beauty and painting arts they had as an Englishman. The exhibition of thumbnails of Catskill landscapes helped him to rise to fame and attracted the attention of both Asher B. Durand, who would become his lifelong friend, and key figures in the New York City art scene. While traveling abroad, Cole met many wealthy Americans and received many orders from them. All these circumstances increased his reputation and prestige. Thomas Cole died on February 11, 1848. He pioneered the first native American painting and went down in history as the first environmentalist painter in American painting. With his paintings, he inspired not only American painters, but all over the world, to explain environmental problems with their art, and led to the emergence of many environmentalist painters.Thomas Cole is an American artist.He is one of the America's distinguished landscape painters in the nineteenth century.He was born on February 1, 1801 in Bolton-le-Moor, England,United Kingdom.He was working as an engraver's assistant and as an apprentice to a designer of calico prints before emigrating with his family to the United States of America in 1818, Cole worked briefly as an engraver in Philadelphia before joining his family in Steubenville, Ohio, in 1819. While in Ohio he obviously learned the aspects of oil painting from an nomadic portrait painter called Stein. In 1823,while a staying in Pittsburgh, Cole started drawing from nature, creating closely observed and extensively expressive images of trees branches,flowers and lakes. After that he returned to Philadelphia, where he studied at the Pennsylvania Academy of the Fine Arts and worked in a various art-related jobs.In April 1825 Cole moved to New York, where his family had been living. Besides at the same summer, he made a broad sketching tours for the Hudson River and into the Catskill Mountains.Moreover, In late October 1825 three of his landscapes were sold to three outstanding figures in the young nation's art community, John Trumbull (1756-1843), William Dunlap (1766-1839), and Asher B. Durand (1796-1886). In January 1826 Cole was elected a founding member of the National Academy of Design, and his works were more and more in demand with leading patrons such as Daniel Wadsworth (1771-1848) of Hartford and Robert Gilmor, Jr. (1774-1848) of Baltimore.Although Cole had abundant commissions in the late 1820 s to paint pictures of American scenery, his ambition was to create a "higher style of landscape" that could express moral or religious meanings. His first major efforts in this way integrated with mixed reviews, and he decided to study and travel in Europe were necessary for him. In June 1829 Cole sailed for England, where he studied the works of Old Masters and also met Joseph Mallord William Turner (1775-1851) and John Constable (17761837). He subsequently traveled in France and in Italy, with lengthy stays in Rome and Florence. While in Italy he accepted of a multi-part landscape series tracing the rise and fall of an archetypal civilization. Although he failed to interest Gilmor in commissioning the series, upon his return to America in 1832 Cole did manage to assure the retired New York merchant Luman Reed (1785-1836) to support his grand project. Finally, the five canvas Course of Empire (New-York Historical Society), was completed in 1836 and received considerable popular attention and generally favorable reviews.Cole continued to paint American landscapes in the 1830 s and early 1840 s, but much of his energy in these years went into the creation of complex imaginary works such as The Departure and The Return (1837, National Gallery of Art, Washington, D.C., Corcoran Collection) and the two versions of The Voyage of Life (1839-1840, Munson-Williams-Proctor Institute, Utica, and 1842, National Gallery of Art, Washington, D.C.). In 1836 he married Maria Barstow and settled in Catskill, New York, a small village on the west side of the Hudson and close to the Catskill Mountains. That same year Cole, who was throughout his career a prolific writer of prose and poetry, published his "Essay on American Scenery" in the American Monthly Magazine, where he expressed many of his most deeply felt opinions on landscape painting.In 1841 Cole make a second trip abroad, with considerable travel in Italy, covering a memorable visit to Sicily that resulted in several views of Mt. Etna. He returned to Catskill in 1842; in 1844 he accepted the young Frederic Edwin Church as a pupil on Daniel Wadsworth's recommendation. In the mid and late 1840s Cole painted many impressive American landscapes, which are notable for an increased accuracy in the depiction of atmosphere and light. At the same time he labored, ultimately without success, to complete a five-part series called The Cross and the World, in which he endeavored to portray the individual's quest for spiritual knowledge and salvation.Cole's premature death in Catskill on February 11, 1848, was universally mourned and a comprehensive memorial exhibition of his works was quickly organized in New York. His influence on the course of American landscape painting was profound and his works influenced numerous younger painters who matured in the late 1840 s and early 1850s, most importantly Jasper F. Cropsey and Church. 